\title{
LEI DA PALMADA: REFLEXÕES E IMPLICAÇÕES PSICOJURÍDICAS
}

\section{SLAP LAW: REFLECTIONS AND IMPLICATIONS PSYCHO JURIDICAL}

\author{
JAQUELINE SiQUeIRA PELLEGRINI \\ Acadêmica do curso de Direito da Universidade Federal de Santa Maria/RS. \\ LetíCIA MAFFINI DE PAIVA \\ Acadêmica do curso de Direito da Universidade Federal de Santa Maria/RS. \\ LOHANA PINHEIRO FELTRIN \\ Acadêmica do curso de Direito da Universidade Federal de Santa Maria/RS. \\ MARINA SOMAVILLA FEVERSANI \\ Acadêmica do curso de Direito da Universidade Federal de Santa Maria/RS.
}

\section{RESUMO}

O objetivo deste trabalho é analisar a interferência do Estado no poder familiar, bem como no que consiste a "Lei da Palmada" e suas consequências na esfera psicológica da criança e do adolescente. Pretende verificar a legislação existente contra os maus-tratos e as mudanças que podem ocorrer com a sanção do referido Projeto de Lei. Como método, utilizou-se o dedutivo e de pesquisa jurisprudencial, no âmbito do Poder Judiciário Gaúcho, a fim de averiguar seu posicionamento nos casos de castigos físicos em menores de idade. Fez-se uma análise interdisciplinar, através de pesquisa bibliográfica, cotejando os aspectos jurídicos com os psicológicos. Concluiu-se que a proposta pouco modificará a condenação por maus-tratos infantis. Não obstante, a palmada com o fito educacional é diferente dos castigos imoderados e, em tese, os pais sabem diferenciá-los. Ressalta-se que os maus-tratos devem ser punidos, mas o Estado não pode interferir na forma como os pais educam os seus filhos.

Palavras-chave: Lei da Palmada; Direito; Psicologia; Estatuto da Criança e do Adolescente.

\begin{abstract}
This work intends analyze the interference of State in family power, as well the Law of Spanking and the consequences in the psychological sphere of the child and adolescent. It pretends check the actual legislation against ill-treatment and the changes that may occur in the Brazilian legislation with the sanction of the mentioned bill. It used the deductive method and jurisprudential research within the Judiciary of the State of Rio Grande do Sul, in order to ascertain their position in cases of physical harm to children. Still, an interdisciplinary analysis, through literature, comparing the legal aspects and the psychological. It possible conclude that the new proposed legislation won't modify the punishment for child abuse. Still, it is clear that spanking with the aim of education is different from abuse and, in theory, the parents know them apart. Is important emphasize that the abuse should be punished, but the State can't interfere in the way how parents raise their children.
\end{abstract}

Keywords: Slap Law; Law; Psychology; Rights of Children and Teenagers. 


\section{SUMÁRIO}

INTRODUÇAO; 1 A INTERVENÇÃO DO ESTADO NO PODER FAMILIAR; 2 O QUE É A “LEI DA PALMADA"; 3 LEGISLAÇÃO VIGENTE E A POSSIBILIDADE DE PROTEÇÃO À INTEGRIDADE FÍSICA DA CRIANÇA E DO ADOLESCENTE; 4 "LEI DA PALMADA" E O POSICIONAMENTO A FAVOR E CONTRA; 5 ANÁLISE INTERDISCIPLINAR: INFLUÊNCIAS PSICOLÓGICAS DA “LEI DA PALMADA”; CONCLUSÃO; REFERÊNCIAS.

\section{INTRODUÇÃO}

O castigo corporal, comumente usado pelos pais ou responsáveis para educar as crianças e adolescentes, com o intuito de coibir comportamentos considerados indesejáveis, se constitui em antiga prática e, mesmo nos dias atuais, é aceitável pela sociedade. Todavia, cada vez mais se pretende proteger a integridade dos menores, visando evitar que tais punições sejam excedidas.

Neste sentido, com o intuito de resguardar as crianças e adolescentes de castigos físicos imoderados, emerge a popular Lei da Palmada, a qual é consistida por dois Projetos de Lei: Projeto de Lei $\mathrm{n}^{\circ}$ 2.654/2003, de autoria da Deputada Maria do Rosário (PT/RS) e o Projeto de Lei $n^{\circ} 7.672 / 2010$, de autoria do Poder Executivo, sendo que ambos foram editados conforme orientação da Organização das Nações Unidas.

Em síntese, o objetivo destas duas propostas é a alteração de dispositivos do Estatuto da Criança e do Adolescente e do Código Civil, com o objetivo de proibir qualquer punição corporal - moderada ou imoderada - como meio educacional.

Todavia, percebe-se que, através da análise e aplicação da legislação vigente é possível proteger crianças e adolescentes de castigos corporais que degradam a sua integridade física e moral, ou seja, protege-os dos maus-tratos, sem que haja necessidade de alteração dos diplomas legais.

Com efeito, já é possível verificar o posicionamento do Judiciário Gaúcho acerca da questão, o qual analisa os casos concretos e avalia se o castigo consiste em uma punição meramente educacional ou se é uma punição desproporcional, com claro intuito de humilhar o jovem ou a criança.

Assim, o objetivo do presente trabalho é analisar a interferência do Estado no poder familiar, bem como no que consiste a Lei da Palmada e suas consequências na esfera psicológica e, por consequência, no comportamento da criança e do adolescente, caso venha a ser aprovada e a palmada educacional não possa mais ser desferida. Não obstante, pretende-se verificar a 
legislação vigente contra maus-tratos e as mudanças que poderão ocorrer, conforme a proposta dos Projetos de Lei $n^{\circ}$ 2.654/2003 e n 7.672/2010.

Para tanto, após uma análise eminentemente bibliográfica acerca da intervenção estatal e dos Projetos de Lei mencionados e, ainda, da observação direta da legislação vigente, realizou-se pesquisa jurisprudencial, no âmbito do Poder Judiciário do Estado do Rio Grande do Sul, para a averiguação do seu posicionamento sobre o tema ora em debate.

Deste modo, utilizou-se o método dedutivo, partindo da generalidade das decisões judiciais encontradas, para concluir pela pertinência ou não da Lei da Palmada, bem como para a realização da análise interdisciplinar, a qual foi efetuada por pesquisa bibliográfica.

Para melhor entendimento da questão, este trabalho está dividido em (1) A intervenção do Estado no Poder Familiar, (2) 0 que é a Lei da Palmada, (3) Legislação vigente e a possibilidade de proteção à integridade física da criança e do adolescente, (4) Lei da Palmada e o posicionamento a favor e contra e (5) Análise interdisciplinar: influências psicológicas da Lei da Palmada.

Deste modo, o próximo tópico analisará a intervenção estatal no pátrio poder.

\section{A INTERVENÇÃO DO ESTADO NO PODER FAMILIAR}

Ao falar sobre a família, há necessidade de se observar as mutações que ocorreram em sua formação, finalidade e função básica no decorrer do tempo. Com o mesmo pensar, Cristina de Oliveira Zamberlam (2001, p. 11) assevera que

nunca antes as coisas haviam mudado tão rapidamente para uma parte tão grande da humanidade. Tudo é afetado: arte, ciência, religião, moralidade, educação, política, economia, vida familiar, até mesmo os aspectos mais íntimos da vida - nada escapa ${ }^{1}$.

Em virtude deste fato, se faz importante entender a evolução do poder familiar, sua nova concepção, seu exercício e os sujeitos que dele fazem parte.

A expressão "poder de família” corresponde ao antigo pátrio poder, que era o direito absoluto e ilimitado que se conferia ao chefe da organização familiar sobre a pessoa dos filhos. Este termo surgiu com a reação do movimento feminista frente ao patriarcado, pois é

${ }^{1}$ ZAMBERLAM, Cristina de Oliveira. Os novos paradigmas da família contemporânea - Uma perspectiva interdisciplinar. Rio de Janeiro: Renovar, 2001. 
expressamente notável que o vocábulo guardava resquícios de uma sociedade patriarcal e flagrantemente machista.

O Código Civil de 1916 assegurava o poder familiar exclusivamente ao marido (pater familias), que por sua vez era o chefe da sociedade conjugal e somente na falta ou impedimento deste é que o poder poderia ser concedido à mulher.

Posteriormente, com o advento da Constituição Federal de 1988, houve uma modificação radical no que concerne ao direito de família. Com efeito, o princípio da igualdade na família consagrou-se ao conceder a isonomia de tratamento entre homem e mulher (artigo $5^{\circ}, \mathrm{I}^{2}$ ), assegurando-lhes direitos e deveres iguais referentes à sociedade conjugal (artigo 226, §5 ${ }^{\circ 3}$ ) e outorgando o exercício conjunto do poder familiar a ambos os genitores.

Sendo assim, com a evolução das entidades familiares e a promulgação da Carta Magna, o Estatuto da Criança e do Adolescente também teve que se ajustar a esta nova realidade. Deste modo, além de coibir qualquer discriminação, privilégio ou distinção entre homem e mulher, no que se refere ao poder familiar, estabeleceu uma maior proteção aos interesses do menor, levando-se em conta as condições e as necessidades que o mesmo possui.

Nesse sentido, leciona Maria Berenice Dias (2010, p. 413) que o poder familiar “deixou de ter um sentido de denominação para se tornar sinônimo de proteção, com mais características de deveres e obrigações dos pais para com os filhos do que de direitos em relação a eles". Com isso, os filhos passaram a sujeitos de direito, ao invés de objetos e o poder familiar deixa de ser um exercício de autoridade para se tornar um encargo dos pais, em função da lei.

Entretanto, existem determinadas situações em que a intervenção do Estado torna-se imperiosa como, por exemplo, aquelas que podem afetar ou prejudicar o pleno desenvolvimento da criança e do adolescente.

Deste modo, pode-se dizer que a proteção da família pelo Estado é um direito subjetivo público. Significa dizer que a família por estar estabelecida em bases aparentemente tão frágeis, constitui uma unidade que necessitada de proteção. Dessa forma, cabe ao poder estatal

\footnotetext{
${ }^{2}$ Art. $5^{\circ}$ Todos são iguais perante a lei, sem distinção de qualquer natureza, garantindo-se aos brasileiros e aos estrangeiros residentes no País a inviolabilidade do direito à vida, à liberdade, à igualdade, à segurança e à propriedade, nos termos seguintes: I - homens e mulheres são iguais em direitos e obrigações, nos termos desta Constituição; (...)

BRASIL. Presidência da República. Constituição Federal de 1988 . Disponível em: <http://www.planalto.gov.br/ccivil_03/Constituicao/Constitui\%C3\%A7ao.htm>. Acesso em: 25 mar. 2012.

${ }^{3}$ Art. 226. A família, base da sociedade, tem especial proteção do Estado. (...) $\S 5^{\circ}$ - Os direitos e deveres referentes à sociedade conjugal são exercidos igualmente pelo homem e pela mulher.

Ibidem.
} 
assegurar o amparo a cada um de seus integrantes, criando mecanismos para coibir a violência no âmbito dessas relações (artigo 226, $\$ 8^{\circ}$, da Constituição Federal ${ }^{4}$ ).

Contudo, o poder do Estado interferir no íntimo familiar encontra limites, não sendo absoluto. Destarte, deve ser norteado pelo princípio da intervenção mínima do Estado no direito de família, porquanto não poderia aquele, sob nenhum pretexto, intervir coercitivamente no âmbito familiar, sob pena de colocar em risco o plano de vida e felicidade de seus membros. Nesse contexto, a proibição da palmada como forma de castigo para fins educacionais e a imposição de sanções para tal comportamento traduz uma afronta a este pressuposto.

Ainda, o Código Civil de 2002, em seu artigo 1.513, disciplina que “é defeso a qualquer pessoa de direito público ou privado interferir na comunhão da vida instituída pela família" ${ }^{\text {. }}$ Dessa forma, percebe-se que cabe aos pais o controle perante a família e a decisão acerca de sua função e ao Estado, em parceria com a sociedade, a responsabilidade de agir frente aos atos praticados em discrepância da lei.

Assevera Silvo de Salvo Venosa que

não pode também o Estado deixar de cumprir sua permanente função social de proteção à família, como sua célula mater, sob pena de o próprio Estado desaparecer, cedendo lugar ao caos. Daí por que a intervenção do Estado na família é fundamental, embora deva preservar os direitos básicos de autonomia. Essa intervenção deve ser sempre protetora, nunca invasiva da vida privada ${ }^{6}$.

Não obstante, conforme dispõe o artigo 229, da Constituição Federal ${ }^{7}$ é dever dos pais garantir aos filhos menores: assistência, criação e educação, os quais são deveres de natureza jurídica, material e moral, respectivamente. Neste passo, todos esses deveres podem ser exigíveis pelo Estado em função dos pais. No entanto, é necessário respeitar o seu livre exercício enquanto não desnaturam em abuso de poder. 0 princípio da autonomia familiar resguarda a ação dos pais, porém, quando os pais falham, cabe ao Estado agir, subsidiariamente ${ }^{8}$.

\footnotetext{
${ }^{4}$ Art. 226. A família, base da sociedade, tem especial proteção do Estado. $\S 8^{\circ}$ - 0 Estado assegurará a assistência à família na pessoa de cada um dos que a integram, criando mecanismos para coibir a violência no âmbito de suas relações.

Ibidem

${ }^{5}$ BRASIL. Presidência da República. Código Civil. Lei no 10.406 de 10 de janeiro de 2002. Disponível em: <http://www.planalto.gov.br/ccivil_03/leis/2002/L10406compilada.htm>. Acesso em: 17 maio 2012.

${ }^{6}$ VENOSA, Sílvio de Salvo. Direito civil: direito de família. $5^{\mathrm{a}}$ ed. São Paulo: Atlas, 2005.

7 BRASIL. Presidência da República. Constituição Federal de 1988. Disponível em: <http://www.planalto.gov.br/ccivil_03/Constituicao/Constitui\%C3\%A7ao.htm>. Acesso em: 25 mar. 2012. ${ }^{8}$ PEREIRA JR, Antonio Jorge. Usurpação do poder familiar e irresponsabilidade do estado na campanha de prevenção de AIDS, DST e gravidez. Disponível em: <http://www.ibdfam.org.br/novosite/artigos/detalhe/618>. Acesso em: 04 de jul. 2012.
} 
Portanto, percebe-se que somente em ocasiões em que prevaleça o interesse coletivo ou público, as decisões tomadas deixam de partir da família como um ente particular, sendo necessária a intervenção do Estado no exercício de suas funções.

No tocante à Lei da Palmada, observa-se o desrespeito às normas supracitadas, ao princípio da intervenção mínima do Estado no direito de família e da autonomia familiar. Isto porque, a família possui o direito de eleger qual a forma de educação será ensinada ao menor, bem como as formas empregadas para tanto, desde que não afronte nenhuma regra de direito material e, tampouco, prejudique o desenvolvimento da criança e do adolescente. Logo, a intervenção do Estado torna-se necessária, no que tange à forma de castigo que o poder familiar resolve empregar, apenas quando a palmada educativa torna-se um ato de espancamento.

Em suma, a Lei da Palmada estabelece um paradoxo. Isto porque a mesma Carta Magna, que confere aos pais o direito e dever de educar seus filhos, dando assistência moral e material, bem como garante a autonomia familiar como consequência da dignidade da pessoa humana, também pretende influenciar a forma como os pais ensinam seus filhos, interferindo na vida privada.

Como explicitado, a Lei da Palmada é um exemplo da interferência estatal no poder familiar e, deste modo, importante tecer algumas considerações sobre ela, como será feito no próximo tópico.

\section{O QUE É A “LEI DA PALMADA”}

A popular "Lei da Palmada", em verdade, consiste na pretensão de alteração de artigos de leis vigentes, tais como o Estatuto da Criança e do Adolescente e o Código Civil. Neste sentido, propõe-se a proibição de qualquer tipo de castigo físico, moderado ou imoderado, em crianças e adolescentes, mesmo com fim pedagógico e educativo.

A primeira tentativa de coibir o uso de violência contra menores de idade foi com o Projeto de Lei $n^{\circ}$ 2.654/2003, criado pelada Deputada Maria do Rosário do PT/RS, o qual seguiu orientação da Organização das Nações Unidas, em decorrência da Convenção Internacional sobre os Direitos da Criança, aprovada em 20 de novembro de 1989, pela Assembléia Geral das Nações 
Unidas. Entretanto, desde 2006, este Projeto de Lei encontra-se na Mesa Diretora da Câmara dos Deputados, sem movimentação9.

Com efeito, o Projeto proposto pela Deputada Maria do Rosário, propunha o acréscimos dos artigos 18-A, 18-B e 18-D-C ao Estatuto da Criança e do Adolescente. 0 artigo 18-A dispõe que as crianças e adolescentes têm direito a não serem submetidas à castigos físicos, mesmo com o intuito educacional:

Art. 18-A. A criança e o adolescente têm direito a não serem submetidos a qualquer forma de punição corporal, mediante a adoção de castigos moderados ou imoderados, sob a alegação de quaisquer propósitos, no lar, na escola, em instituição de atendimento público ou privado ou em locais públicos.

Parágrafo único - Para efeito deste artigo será conferida especial proteção à situação de vulnerabilidade à violência que a criança e o adolescente possam sofrer em consequiência, entre outras, de sua raça, etnia, gênero ou situação sócio-econômica ${ }^{10}$.

Por sua vez, o artigo 18-B, assegura que, constatada a hipótese de punição corporal, os pais, professor e responsáveis ficarão sujeitos a uma série de sanções como, encaminhamento a cursos ou programas de orientação, por exemplo.

Art. 18-B. Verificada a hipótese de punição corporal em face de criança ou adolescente, sob a alegação de quaisquer propósitos, ainda que pedagógicos, os pais, professores ou responsáveis ficarão sujeitos às medidas previstas no artigo 129, incisos I, III, IV e VI desta lei, sem prejuízo de outras sanções cabíveis.

(Art. 129. São medidas aplicáveis aos pais ou responsável:

I - encaminhamento a programa oficial ou comunitário de proteção à família;

III - encaminhamento a tratamento psicológico ou psiquiátrico;

IV - encaminhamento a cursos ou programas de orientação;

$\mathrm{VI}$ - obrigação de encaminhar a criança ou adolescente a tratamento especializado ${ }^{11}$.

Ainda, o artigo 18-D traz a responsabilidade do Estado no estímulo de ações educativas, divulgação de meios à proteção contra a violência e promoção de reformas curriculares:

Art. 18-D. Cabe ao Estado, com a participação da sociedade:

I. Estimular ações educativas continuadas destinadas a conscientizar o público sobre a ilicitude do uso da violência contra criança e adolescente, ainda que sob a alegação de propósitos pedagógicos;

II. Divulgar instrumentos nacionais e internacionais de proteção dos direitos da criança e do adolescente;

\footnotetext{
${ }^{9}$ BRASIL. Câmara dos Deputados. Projeto de Lei ${ }^{\circ} 2.654$ de 02 de dezembro de 2003. Disponível em: <http://www.camara.gov.br/sileg/integras/186335.pdf>. Acesso em: 16 abr. 2012.

${ }^{10}$ Ibidem.

${ }^{11}$ Ibidem.
} 
III. Promover reformas curriculares, com vistas a introduzir disciplinas voltadas à proteção dos direitos da criança e do adolescente, nos termos dos artigos 27 e 35, da Lei 9394, de 20/12/1996 e do artigo $1^{\circ}$ da Lei 5692, de $11 / 08 / 1971$, ou a introduzir no currículo do ensino básico e médio um tema transversal referente aos direitos da criança, nos moldes dos Parâmetros Curriculares Nacionais ${ }^{12}$.

Não obstante, o referido Projeto de Lei, buscava significativa alteração no artigo 1.634, do Código Civil $^{13}$, alterando a redação atual para “Art. 1634: Compete aos pais, quanto à pessoa dos filhos menores: VII. Exigir, sem o uso de força física, moderada ou imoderada, que lhes prestem obediência, respeito e os serviços próprios de sua idade e condição ${ }^{14 \text { ". }}$

Com esta alteração, o dever de educação dos pais, não poderá ser exercido com agressões físicas e castigos, persistindo ainda a necessidade de obediência e respeito dos filhos para com os pais, conforme se depreende da redação proposta pelo Projeto de Lei.

Em que pese a existência do Projeto de Lei $n^{\circ} 2.654 / 2003$, atendendo nova disposição da Organização das Nações Unidas, editada por meio do Comentário Geral n 8/2006, aprovada no feito da $42^{\mathrm{a}}$ sessão do Comitê dos Direitos da Criança, em Genebra, no dia 02 de junho de 2005, novo Projeto de Lei foi remetido à apreciação.

Este, contudo, é de autoria do Poder Executivo e foi numerado como Projeto de Lei $\mathrm{n}^{\circ}$ 7.672/2010. Diferentemente do anterior, este Projeto de Lei encontra-se em movimentação, aguardando apreciação pelo Senado Federal ${ }^{15}$.

Por sua vez, o Projeto de Lei $n^{\circ} 7.672 / 2010$, pretende acrescer ao Estatuto da Criança e do Adolescente os artigos 17-A e 70-A. 0 artigo 17-A assevera que a criança e o adolescente têm direito de serem cuidados pelos pais, os quais devem educar sem o uso de castigo corporal:

Art. 17-A. A criança e o adolescente têm o direito de serem educados e cuidados pelos pais, pelos integrantes da família ampliada, pelos responsáveis ou por qualquer pessoa encarregada de cuidar, tratar, educar ou vigiar, sem o uso de castigo corporal ou de tratamento cruel ou degradante, como formas de correção, disciplina, educação, ou qualquer outro pretexto.

Parágrafo único. Para os efeitos desta Lei, considera-se:

I - castigo corporal: ação de natureza disciplinar ou punitiva com o uso da força física que resulte em dor ou lesão à criança ou adolescente.

\footnotetext{
12 Ibidem

${ }^{13}$ Atual redação do artigo: Art. 1.634. Compete aos pais, quanto à pessoa dos filhos menores: (...) VII exigir que lhes prestem obediência, respeito e os serviços próprios de sua idade e condição.

BRASIL. Presidência da República. Código Civil. Lei $\mathrm{n}^{\circ} 10.406$ de 10 de janeiro de 2002. Disponível em: <http://www.planalto.gov.br/ccivil_03/leis/2002/L10406compilada.htm>. Acesso em: 17 maio 2012.

${ }^{14}$ BRASIL. Câmara dos Deputados. Projeto de Lei n ${ }^{\circ} 2.654$ de 02 de dezembro de 2003. Disponível em: <http://www.camara.gov.br/sileg/integras/186335.pdf>. Acesso em: 16 abr. 2012

15 Ibidem.
} 
II - tratamento cruel ou degradante: conduta que humilhe, ameace gravemente ou ridicularize a criança ou o adolescente.

Art. 17-B. Os pais, integrantes da família ampliada, responsáveis ou qualquer outra pessoa encarregada de cuidar, tratar, educar ou vigiar crianças e adolescentes que utilizarem castigo corporal ou tratamento cruel ou degradante como formas de correção, disciplina, educação, ou a qualquer outro pretexto estarão sujeitos às medidas previstas no art. 129, incisos I, III, IV, VI e VII, desta Lei, sem prejuízo de outras sanções cabíveis ${ }^{16}$.

Já o artigo 70-A, garante que a União, os Estados, o Distrito Federal e os Municípios atuarão juntamente para elaboração de políticas públicas com o fito de impedir o castigo físico em crianças e adolescentes:

Art. 70-A. A União, os Estados, o Distrito Federal e os Municípios atuarão de forma articulada na elaboração de políticas públicas e execução de ações destinadas a coibir o uso de castigo corporal ou de tratamento cruel ou degradante, tendo como principais ações:

I - a promoção e a realização de campanhas educativas e a divulgação desta Lei e dos instrumentos de proteção aos direitos humanos; II - a inclusão nos currículos escolares, em todos os níveis de ensino, de conteúdos relativos aos direitos humanos e prevenção de todas as formas de violência contra a criança e o adolescente;

III - a integração com os órgãos do Poder Judiciário, do Ministério Público, da Defensoria Pública, do Conselho Tutelar da Criança e do Adolescente nos Estados, Distrito Federal e nos Municípios, Conselhos de Direitos da Criança e do Adolescente, e entidades não governamentais;

IV - a formação continuada dos profissionais que atuem na promoção dos direitos de crianças e adolescentes; e $\mathrm{V}$ - o apoio e incentivo às práticas de resolução pacífica de conflitos que envolvam violência contra criança e adolescente ${ }^{17}$.

Neste sentido, importante observar que o Projeto de Lei $n^{\circ} 7.672 / 2010$, diferentemente do anterior, apresenta-se mais completo e robusto, pois além da proibir castigos físicos, impede a prática de qualquer ato degradante que gere humilhação ou possa diminuir a criança ou adolescente frente aos adultos.

Portanto, ambos os Projetos de Lei visam prioritariamente, abolir o uso de corretivos corporais e tratamento desprezível na educação de crianças, protegendo, dessa forma, a integridade dos jovens e a dignidade da pessoa humana desde tenra idade. Contudo, a legislação esparsa brasileira já prevê a proteção da criança e do adolescente, bem como limita o uso de castigo físico com o intuito educativo.

\footnotetext{
${ }^{16}$ BRASIL. Câmara dos Deputados. Projeto de Lei ${ }^{\circ} 7.672$ de 16 de julho de 2010. Disponível em: <http://www.camara.gov.br/proposicoesWeb/fichadetramitacao?idProposicao=483933>. Acesso em: 22 maio 2012.

${ }^{17}$ Ibidem.
} 

eficácia.

\section{LEGISLAÇÃO VIGENTE E A POSSIBILIDADE DE PROTEÇÃO À INTEGRIDADE FÍSICA DA CRIANÇA E DO ADOLESCENTE}

Em que pese a pretensão de alteração do Estatuto da Criança e do Adolescente e do Código Civil, com vistas à proteção da criança, percebe-se que a legislação existente já protege os jovens de maus tratos e castigos degradantes à sua integridade. Deste modo, os Projetos de Leis não trazem grandes inovações.

Devido ao poder familiar, os pais possuem certo domínio sobre a vida dos filhos menores, todavia, a legislação existente limita o exercício desse poder com o intuito de resguardar os direitos da criança e do adolescente.

Com efeito, a Constituição Federal, em seu artigo 227 assevera que é dever da família, da sociedade e do Estado colocar a criança, o adolescente e o jovem, a salvo de toda a forma de violência, crueldade e opressão ${ }^{18}$.

Ainda, o próprio Código Civil, no artigo 1.630 assegura que os filhos estão sujeitos ao poder familiar, enquanto menores e que compete aos pais a sua criação e educação, exigindo que lhes prestem obediência, respeito e os serviços próprios de sua idade e condição ${ }^{19}$. Para tanto, em seu artigo 1.638, I, dispõe que perderá, por ato judicial, o poder familiar o pai ou a mãe que castigar imoderadamente o filho ${ }^{20}$.

Não obstante, o Estatuto da Criança e do Adolescente, no seu artigo 17, garante a inviolabilidade da integridade física, psíquica e moral da criança e do adolescente ${ }^{21}$, sendo dever de todos zelar pela dignidade dos mesmos, pondo-os a salvo de qualquer tratamento desumano, violento, aterrorizante, vexatório ou constrangedor, conforme dispõe o artigo $18^{22}$.

\footnotetext{
18 BRASIL. Presidência da República. Constituição Federal de 1988. Disponível em: <http://www.planalto.gov.br/ccivil_03/Constituicao/Constitui\%C3\%A7ao.htm>. Acesso em: 25 mar. 2012

${ }^{19}$ BRASIL. Presidência da República. Código Civil. Lei n 10.406 de 10 de janeiro de 2002. Disponível em: <http://www.planalto.gov.br/ccivil_03/leis/2002/L10406compilada.htm>. Acesso em: 17 maio 2012.

${ }^{20} \mathrm{Ibidem}$

${ }^{21}$ BRASIL. Presidência da República. Estatuto da Criança e do Adolescente. Lei no 8.069 de 13 de julho de 1990. Disponível em: <http://www.planalto.gov.br/ccivil_03/leis/L8069.htm>. Acesso em: 22 maio 2012. ${ }^{22}$ Ibidem.
} 
Além disso, na seara penal, há previsão expressa, no artigo 136 do Código Penal, de punição àquele que expor a perigo a vida ou a saúde de pessoa sob sua autoridade, guarda ou vigilância, para fim de educação, ensino, tratamento ou custódia, abusando de meios de correção ou disciplina. A pena varia de dois a um ano e multa e, ainda, se o fato resultar de lesão corporal de natureza grave a pena é de reclusão de um a quatro anos e se resultar na morte, a punição é de reclusão de quatro a doze anos. Ressalta-se que a pena aumenta um terço se o crime é praticado contra menores de 14 anos $^{23}$.

Portanto, com a atual legislação em vigor, há previsão de proteção da integridade física e moral da criança e do adolescente. Neste passo, o Poder Judiciário, ante a aplicação da legislação acima esposada, tem se posicionado no sentido de não penalizar os responsáveis pelo castigo, quando o seu intuito é educativo e quando não caracterizado o intuito de maltratar.

Assim, na apelação cível $n^{\circ} 71003450418$, do Tribunal de Justiça do Rio Grande do Sul, de relatoria do Desembargador Heleno Tregnago Saraiva e julgada em 09/04/2012, entendeu-se que no castigo perpetrado não houve a vontade de maltratar a vítima, de modo a expor a perigo a sua vida ou saúde, mas tão somente de aplicar castigo educacional:

APELAÇÃO CRIME. MAUS-TRATOS. ART. 136, CAPUT, DO CÓDIGO PENAL. SENTENÇA ABSOLUTÓRIA MANTIDA. Elementos de prova carreados aos autos que não permitem concluir pela existência do elemento subjetivo do tipo, que é a vontade consciente de maltratar a vítima, de modo a expor a perigo a sua vida ou saúde. RECURSO IMPROVIDO ${ }^{24}$.

No mesmo sentido, a apelação cível $n^{\circ}$ 71002907194, da Turma Recursal Criminal do Tribunal de Justiça do Rio Grande do Sul, de relatoria do Desembargador Edson Jorge Cechet e julgada em 13/12/2010:

APELAÇÃO CRIME. MAUS TRATOS. ART. 136 DO CÓDIGO PENAL. SENTENÇA ABSOLUTÓRIA MANTIDA. Muito embora a prova judicializada tenha confirmado que a mãe desferiu tapas no filho, não há prova de que sua conduta tenha sido a de abusar no modo de correção, e sim de proceder à correção das atitudes do filho, em busca de quem teve de sair em plena madrugada. Elemento subjetivo ausente em episódio isolado que, além disso, teve seu resultado vinculado a hemorragia nasal que acomete a vítima. Sentença absolutória mantida. APELAÇÃO IMPROVIDA ${ }^{25}$.

${ }^{23}$ BRASIL. Presidência da República. Código Penal. Decreto-Lei n 2.848 de 7 de dezembro de 1940. Disponível em: <http://www.planalto.gov.br/ccivil_03/decreto-lei/del2848.htm>. Acesso em: 21 maio 2012.

${ }^{24}$ Ibidem

${ }^{25}$ BRASIL. Câmara dos Deputados. Projeto de Lei $n^{\circ} 7.672$ de 16 de julho de 2010. Disponível em: <http://www.camara.gov.br/proposicoesWeb/fichadetramitacao?idProposicao=483933>. Acesso em 22 mai. 2012. 
Percebe-se, deste modo, que não é qualquer castigo físico que é caracterizado como maus-tratos, eis que é dever da família educar os filhos, sendo que a "palmada educadora" é diferente dos castigos abusivos que comprometem a integridade física e moral do indivíduo.

Sendo assim, questiona-se a real efetividade da "Lei da Palmada" eis que a interpretação sobre que tipo de castigo resulta em sofrimento ficará a cargo da Justiça, como atualmente ocorre e porque, em verdade, os Projetos de Lei não trazem nenhuma alteração, apenas advertências, inclusão da família em programas sociais e multas para quem não denunciar os maus tratos.

Neste sentido, segundo o Presidente da OAB, Ophir Cavalcante

A lei, sozinha, pode ficar sem eficácia, pois a palmada como forma de educar é algo cultural neste país. Temos de ter campanhas educativas e de planejamento por parte do Poder Público para informar as famílias sobre a melhor forma de ensinar as crianças. Esse é um dever do Estado que, lamentavelmente, não tem estrutura para isso. A lei pode cair no vazio ${ }^{26}$.

A repercussão gerada pelo debate dos Projetos de Lei se tornou de grande proporção, colocando em contenda os defensores das alterações contra aqueles que não vêem estas como as soluções para o fim do castigo físico no âmbito familiar. Assim, imperioso analisar as opiniões favoráveis e contra os Projetos de Lei, o que será feito no próximo tópico.

\section{4. “LEI DA PALMADA" E O POSICIONAMENTO A FAVOR E CONTRA}

De modo geral, os brasileiros não aprovam os Projetos de Lei que pretendem proibir a palmada e os castigos físicos como forma educativa. Com efeito, em pesquisa realizada pela Datafolha, em julho de 2010, em todo o país, 54\% dos 10.905 entrevistados disseram-se contra e apenas $36 \%$ revelaram ser favoráveis ${ }^{27}$.

Os opositores da "Lei da Palmada" afirmam que esta norma prejudicará a autoridade dos pais sobre os seus filhos e, assim, as crianças serão educadas sem limites, tornando-se maleducadas. Ainda, segundo a Folha de São Paulo de 27 de julho de 2010, entre os argumentos dos

${ }^{26}$ OAB: lei da palmada será inócua sem políticas efetivas de educação familiar. Disponível em: <http://agenciabrasil.ebc.com.br/noticia/2011-12-15/para-oab-lei-da-palmada-sem-orientacao-familiare-inocua>. Acesso em: 16 abr. 2012.

${ }^{27}$ FAORO, Atílio. 0 Brasil não quer a lei da palmada, Sr. Presidente! Disponível em: <http://www.ipco.org.br/home/nacional/o-brasil-nao-quer-a-lei-da-palmada-sr-presidente>. Acesso em: $21 \mathrm{abr} .2012$. 
que são contra os Projetos de Lei, destaca-se a defesa do espaço privado, da casa, onde não competiria ao Estado interferir ${ }^{28}$.

Um dos principais opositores a proposta, o Deputado Jair Bolsonaro, afirma que a proposta desautoriza os pais e cria uma cultura de filhos que podem denunciar suas famílias, bem como prejudica a educação e favorece a delinquência e o crime ${ }^{29}$.

Os opositores da Lei da Palmada afirmam que esta norma prejudicará a autoridade dos pais sobre os seus filhos e, assim, as crianças serão educadas sem limites, tornando-se maleducadas. Ainda, segundo a Folha de São Paulo de 27 de julho de 2010, entre os argumentos dos que são contra os Projetos de Lei, destaca-se a defesa do espaço privado, da casa, onde não competiria ao Estado interferir ${ }^{30}$.

Um dos principais opositores a proposta, o Deputado Jair Bolsonaro, afirma que a proposta desautoriza os pais e cria uma cultura de filhos que podem denunciar suas famílias, bem como prejudica a educação e favorece a delinquência e o crime ${ }^{31}$.

Com efeito, a alteração do Estatuto da Criança e do Adolescente é desnecessária, tendo em vista que, como demonstrado anteriormente, abusos nos meios de correção já são proibidos. Ainda, ressalta-se que

O pai não poderá mais dar uma palmada no seu filho menor com o intuito de educá-lo e o Estado terá como função fiscalizar se os pais não estão batendo em seus filhos. Assim o poder familiar seria controlado pelo Estado. 0 Estado assumirá, com a aprovação da lei, o dever de fiscalizar e punir palmadas que os pais praticarem contra seus filhos. As crianças e adolescentes não poderão mais sofrer qualquer tipo de violência física o que seria no ponto de vista dos opositores uma ofensa ao poder familiar. ${ }^{32}$

Não obstante, a psicóloga Olga Tessari discorda do projeto de lei e acredita que "os pais amam seus filhos e de forma alguma querem agredi-los. Isso é usado quando todos os recursos acabam. É impossível educar um filho sem um castigo físico”33.

\footnotetext{
${ }^{28}$ Ibidem

29 SOUZA, Nayane Valente de. Poder Familiar: os limites dos castigos nos filhos. Disponível em <http://repositorio.uniceub.br/bitstream/123456789/1408/1/20725581.pdf > Acesso em 20 mai. 2012.

30 FAORO, Atílio. O Brasil não quer a lei da palmada, Sr. Presidente! Disponível em <http://www.ipco.org.br/home/nacional/o-brasil-nao-quer-a-lei-da-palmada-sr-presidente> Acesso em 21 abr. 2012.

31 SOUZA, Nayane Valente de. Poder Familiar: os limites dos castigos nos filhos. Disponível em <http://repositorio.uniceub.br/bitstream/123456789/1408/1/20725581.pdf > Acesso em 20 mai. 2012.

32 Ibidem
}

33 SE APROVADA, Lei da Palmada pode não ter eficácia. Disponível em: <http://veja.abril.com.br/noticia/brasil/se-aprovada-lei-da-palmada-pode-nao-ter-eficacia>. Acesso em: 21 maio 2012. 
De outro lado, quem é favorável à alteração da legislação argumenta que a punição corporal é uma ofensa à integridade física e à dignidade da criança e do adolescente. Assim, a autora do Projeto de Lei $n^{\circ}$ 2654/2003, Maria do Rosário, justifica a necessidade de alteração do Estatuto da Criança e do Adolescente devido ao fato de que as crianças e adolescentes são sujeitos em condição especial de desenvolvimento ${ }^{34}$.

No ordenamento jurídico brasileiro é permitido o uso de violência moderada, sendo a violência imoderada expressamente proibida. Neste contexto, os favoráveis aos Projetos de Lei argumentam de que a permissão do castigo moderado gera dificuldade de limitar o uso desse castigo, propiciando abusos.

Ainda, para o psicólogo Cristiano Longo, o castigo físico pode gerar consequências, de modo que a criança pode desenvolver um sentimento de inferioridade e inadequação ou começar a mentir para evitar a punição e, como ela não pode bater nos pais, vai descontar nos irmãos ou em colegas menores ${ }^{35}$.

Entretanto, segundo a pesquisa realizada pelo Datafolha ${ }^{36}$ a palmada está incorporada à cultura e é vista como um instrumento tradicional e aceitável para educar as crianças e, aos brasileiros, não falta o bom senso. Neste passo, a maioria das pessoas saberia distinguir entre a palmada eventual e o mau trato às crianças.

Ante todas estas considerações, imperiosa a análise interdisciplinar da "Lei da Palmada", com o objetivo de sopesar as consequências psicológicas na sua aprovação, como será averiguado no tópico seguinte.

\section{ANÁLISE INTERDISCIPLINAR: INFLUÊNCIAS PSICOLÓGICAS DA “LEI DA PALMDA"}

Com as informações já apresentadas, convém ressaltar todo viés psicológico e pedagógico contido nas alterações previstas por estes Projetos de Lei, caso aprovados. Com efeito, a

\footnotetext{
34 SOUZA, Nayane Valente de. Poder Familiar: os limites dos castigos nos filhos. Disponível em: <http://repositorio.uniceub.br/bitstream/123456789/1408/1/20725581.pdf>. Acesso em: 20 maio 2012.

35 SE APROVADA, Lei da Palmada pode não ter eficácia. Disponível em: <http://veja.abril.com.br/noticia/brasil/se-aprovada-lei-da-palmada-pode-nao-ter-eficacia>. Acesso em: 21 maio 2012.

36 FAORO, Atílio. O Brasil não quer a lei da palmada, Sr. Presidente! Disponível em: <http://www.ipco.org.br/home/nacional/o-brasil-nao-quer-a-lei-da-palmada-sr-presidente>. Acesso em: 21 abr. 2012.
} 
sociedade abarca em suas raízes o castigo físico como meio educacional, sendo que a própria Bíblia, livro que guiou toda sociedade Cristã por muitos séculos traz junto as suas escritas o seguinte Provérbio, 13:24 "aquele que poupa a vara odeia o filho, mas aquele que o ama tem o cuidado de discipliná-lo"37.

Com isso, percebe-se que os Cristãos aceitavam o uso de castigos físicos como meio educacional e, sob esta ótica, repreensões não necessariamente seriam interpretadas como absurdo. Em décadas passadas era compreensível, inclusive, a punição dentro de sala de aula, como crianças ajoelhadas no milho, usando chapéu de burro e com o uso da palmatória, por exemplo. Na educação atual, aparentemente, família e escola, são contra os castigos físicos em crianças e adolescentes e, no lugar dos castigos físicos pretende-se o diálogo.

Hannah Arendt, filósofa alemã, apresenta um discurso onde discorda da violência como fonte de autoridade. Para ela, a autoridade pessoal (pai e filho) não necessita de violência, pois se caracteriza pelo reconhecimento, isto é, não é necessário imposição, persuasão, ela se mantém por si só.

A violência pode gerar o vigor que é a extensão de uma independência. A força, que é utilizada como sinônimo de violência, apesar de terem conceitos diferentes, é que pode gerar um poder, apesar de que este tende ao fracasso, pois o poder deve ser investido e não imposto. Nestes moldes a violência não seria fonte geradora de autoridade, seria na verdade a imposição de algo visando a um efeito imediato, mas fadado ao fracasso ${ }^{38}$.

Todavia, entre psicólogos e pedagogos as opiniões são divergentes e, para que seja possível a análise interdisciplinar, alguns conceitos iniciais precisam ser apresentados.

Neste passo, para os profissionais que seguem a linha psicanalítica, dos 07 (sete) aos 10 (dez) anos de idade a criança passa pela fase de desenvolvimento chamada "Complexo de Édipo". Neste momento, deve ocorrer uma ruptura entre a relação mãe e filho. Para tanto, a figura do pai é inserida na relação, vindo com a finalidade de ser alguém que irá apresentar as regras sociais, as normas, a lei e o limite. A inserção do pai, com as atitudes destacadas é chamada de castração. Nos ensinamentos de Freud, o Complexo de Édipo e castração são apresentados da seguinte maneira:

No caso do menino, o pêndulo pesa mais para o lado do castigo. A castração aparece para o menino como um castigo por ter desejado a mãe. A promessa

\footnotetext{
${ }^{37}$ BÍBLIA Sagrada: Edição Pastoral. São Paulo: Paulus, 1990.

${ }^{38}$ ARENDT. Hannah. Da Violência. Tradução de Maria Cláudia Drummond Trindade. Brasília: Universidade de Brasília, 1985.
} 
entra em cena, secundariamente, como possibilidade de desejar. Calligaris (1996), refletindo sobre a função do pai enquanto interdito, revela: "O que me é proibido, os limites que me são impostos como criança, é justamente o que me outorga e me permite reconhecer o meu lugar, o lugar de filho" (Calligaris, 1996: 43) E podemos acrescentar que este interdito instaura a possibilidade do desejo, porque a condição do desejo é a falta. ${ }^{39}$

Através das teorias Freudianas fica explicito que quem tem o papel de castigar, como se percebe do seguinte excerto:

No texto sobre Moisés, Freud demonstra que um homem só é pai na medida em que se reconhece como filho (Marcos, 2003: 31). Moisés é descrito como um pai autoritário, o que acaba por provocar revoltas de seu povo. Revoltas estas suprimidas mediante sangrentos castigos (Freud, [1939] 1976). A tese freudiana é de que Moisés tenha sido morto pelos judeus, uma analogia ao pai que acaba sendo vítima do filho. ${ }^{40}$

Em um contraponto, na atualidade, muitos lares são regidos apenas pelas mães, o que não limita que a castração seja exercida pela figura feminina. Todavia, como mostra o trecho a seguir, a falta da figura paterna pode vir a acarretar possíveis problemas de estruturação psíquica, caso este momento não seja muito bem conduzido por aquele que assumir este papel.

A queda narcísica está relacionada ao fim das certezas que o encontro com a castração provoca. Muitos homens não suportam este lugar. É o momento propício para a irrupção da psicose em alguns casos. Hoje, verificamos também o grande aumento de famílias "sem pai", ou seja, mulheres que sozinhas criam os filhos. Seria uma opção destas mulheres? Ou, pelo contrário, uma constatação de que os antigos companheiros, pais de seus filhos, não suportaram tal compromisso? ${ }^{41}$

Assim, faz-se mister existir uma figura autoritária impondo regras às crianças. Esses limites também podem ser considerados repreensão por terem ultrapassado as normas apreendidas. Portanto, de nada adianta a criança receber palmadas ou castigos físicos se não foi explicado o porquê dessa punição. Conforme assevera a educadora Tania Zagury,

Como saber a hora de dizer sim e a hora de dizer não? Aliás, perguntam-se, aflitos, muitos pais, há, de acordo com essas novas teorias, realmente uma hora para dizer não? Negar alguma coisa para os filhos parece um crime, um verdadeiro pecado atualmente, ou, no mínimo, um ato autoritário, um modelo antiquado de educar. (...) É fundamental acreditar que dar limites aos filhos é iniciar o processo de compreensão e apreensão do outro (atualmente muita gente acredita que o limite provoca necessariamente um trauma psicológico e, em

39 MOREIRA, Jacqueline de Oliveira; BORGES, Adriana Araújo Pereira. A Castração e Seus Destinos na Construção da Paternidade. Rio de Janeiro: Psicologia Clínica, 2008. p. 75.

40 Ibidem, p. 79.

41 Ibidem, p. 80. 
consequência, acaba abrindo mão desse elemento fundamenta] na educação). Ninguém pode respeitar seus semelhantes se não aprender quais são os seus limites - e isso inclui compreender que nem sempre se pode fazer tudo que se deseja na vida. É necessário que a criança interiorize a ideia de que poderá fazer muitas, milhares, a maioria das coisas que deseja - mas nem tudo e nem sempre. Essa diferença pode parecer sutil, mas é fundamental. Entre satisfazer o próprio desejo e pensar no direito do outro, muitos tendem a preferir satisfazer o próprio desejo, ainda que, por vezes, prejudique alguém. (...) 0 pai que tem autoridade, por outro lado, ouve e respeita seu filho, mas pode, por vezes, ter de agir de forma mais dura do que gostaria, às vezes até impositivamente, mas sempre o objetivo será o bem-estar do filho, protegê-lo de algum perigo ou orientá-lo em direção à cidadania. ${ }^{42}$

A questão a ser analisada é que a educação de crianças exige limites, e tendo em vista toda a construção teórica apresentada, aparentemente algumas palmadas não irão afetar o desenvolvimento infantil, muito menos deixá-las com traumas psicológicos. 0 bom senso deve ser sempre utilizado e uma palmada educacional difere de maus tratos infantis. Em outras palavras, dar limites absolutamente não se choca - nem é o oposto, como muitos pensam - com dar amor, carinho, atenção e segurança. ${ }^{43}$

No momento que o Estado define que a conduta mais conhecida pelos pais atualmente em matéria de educação dos filhos não pode mais ser utilizada, deixa muitos deles sem saber como agir. O Estado, com a "Lei da Palmada", se realmente colocada em vigor, irá impedir que pais castiguem os filhos, deixando muitas dessas crianças sem saber o que é certo e o que é errado. Conforme Tania Zagury os reflexos de uma educação sem limites são os seguintes:

$1^{\text {a }}$ ETAPA - Descontrole emocional, histeria, ataques de raiva;

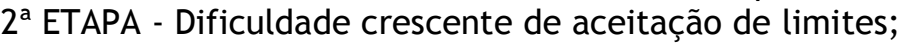

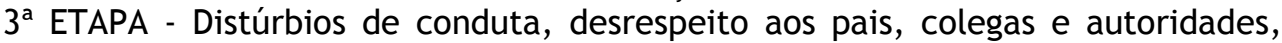
incapacidade de concentração, dificuldade para concluir tarefas, excitabilidade, baixo rendimento;

$4^{a}$ ETAPA - Agressões físicas se contrariado, descontrole, problemas de conduta, problemas psiquiátricos nos casos em que há predisposição. ${ }^{44}$

Muitos jovens que batem hoje a porta do Judiciário por pequenos delitos, ou crimes maiores, podem ser reflexos de uma educação desregrada. Esses, em situação de risco, são aquelas crianças que nunca tiveram nenhum tipo de modelo, muito menos de estrutura, não lhes foi ensinado o certo e o errado, não foram corrigidas atitudes em desacordo com os padrões sociais em que vivemos.

\footnotetext{
${ }^{42}$ ZAGURY. Tania. Limites sem Trauma, construindo cidadãos. $4^{\mathrm{a}}$ ed. São Paulo: Record, 2004. p. 78.

${ }^{43}$ Ibidem, p. 97.

${ }^{44}$ Ibidem, p. 132.
} 
Deste modo, o Estado com essa nova normativa, caso em vigor e utilizada, poderá estar criando um problema para si, tendo que arcar com o prejuízo de ter esses adolescentes delinquentes nos Tribunais.

Assim, faz-se necessário questionar: com esta alteração no Estatuto da Criança e do Adolescente e no Código Civil, o Estado não estará desautorizando a instituição familiar? Não está transferindo as responsabilidades para outras instituições como a escola, por exemplo? E, num futuro próximo, não estará cumulando para si a necessidade de impor limites através da lei à estas crianças, futuros adultos?

Ressalta-se, neste sentido, que a delinquência não decorre tão somente da inexistência de castigos físicos às crianças e adolescentes, com o intuito de educá-las, eis que vários fatores interferem, todavia, por certo que não punir o comportamento errado ajuda para que ela aconteça.

\section{CONCLUSÃO}

A família é a forma de organização mais relevante no que concerne a transmissão de valores, normas e modelo de conduta. Cabe a ela estabelecer estes limites aos seus integrantes, orientando-os no sentido de torná-los cidadãos de direitos e deveres, cabendo ao Estado subsidiariamente tomar para si tal dever. Sendo assim, ao intervir na unidade familiar e na cultura de corrigir com palmada aqueles atos que extrapolem o comportamento cotidiano aceitável o Estado, por vezes, acaba interferindo na vida privada.

$\mathrm{O}$ texto da lei defende a criança e o adolescente têm o direito de serem educados e receberem os devidos cuidados sem o uso de castigos corporais, tratamento cruel ou degradante. No entanto, os maus-tratos e o castigo físico com o intuito educacional são distintos, fazendo-se necessário ressaltar que há enquadramento legal para qualquer tipo de abuso cometido no tratamento às crianças, o qual deverá imposto ao agressor.

Em determinados casos, a palmada é algo salutar e, geralmente é usada quando já se esgotaram todos os meios educativos que podem impor limites às crianças e aos adolescentes. Neste passo, se as experiências na infância determinam a personalidade, as crianças e adolescentes carentes de punições que efetivamente gerem algum sentimento de perda e até mesmo de mesmo de castigo pelo comportamento errado, provavelmente, no futuro, não saberão como reagir ante a situações frustrantes. 
Portanto, deve-se pensar no uso da palmada não como um ato isolado que refletirá internamente em cada pessoa dentro do seio familiar. Deve-se pensar na consequência que o seu uso, ou não, trará para a formação do cidadão e para a sociedade, a médio e longo prazo.

Com efeito, inexiste uma receita para corrigir as falhas ou erros dos filhos, sendo necessário haver sempre uma ponderação dos meios empregados, preservando-se sempre a integridade física e psíquica do menor.

\section{REFERÊNCIAS}

ARENDT. Hannah. Da Violência. Tradução de Maria Cláudia Drummond Trindade. Brasília: Universidade de Brasília, 1985.

BÍBLIA Sagrada: Edição Pastoral. São Paulo: Paulus, 1990.

BRASIL. Câmara dos Deputados. Projeto de Lei n 2.654 de 02 de dezembro de 2003. Disponível em: < http://www.camara.gov.br/sileg/integras/186335.pdf>. Acesso em: 16 abr. 2012.

BRASIL. Câmara dos Deputados. Projeto de Lei $n^{\circ} 7.672$ de 16 de julho de 2010. Disponível em: <http://www.camara.gov.br/proposicoesWeb/fichadetramitacao?idProposicao=483933>. Acesso em: 22 maio 2012.

BRASIL. Presidência da República. Código Civil. Lei no 10.406 de 10 de janeiro de 2002. Disponível em: <http://www.planalto.gov.br/ccivil_03/leis/2002/L10406compilada.htm>. Acesso em: 17 maio 2012.

BRASIL. Presidência da República. Código Penal. Decreto-Lei $n^{\circ} 2.848$ de 7 de dezembro de 1940. Disponível em: <http://www.planalto.gov.br/ccivil_03/decreto-lei/del2848.htm >. Acesso em: 21 maio 2012.

BRASIL. Presidência da República. Constituição Federal de 1988. Disponível em: <http://www.planalto.gov.br/ccivil_03/Constituicao/Constitui\%C3\%A7ao.htm>. Acesso em: 25 mar. 2012.

BRASIL. Presidência da República. Estatuto da Criança e do Adolescente. Lei $n^{\circ} 8.069$ de 13 de julho de 1990. Disponível em: <http://www.planalto.gov.br/ccivil_03/leis/L8069.htm>. Acesso em: 22 maio 2012.

DIAS, Maria Berenice, Manual de direito das famílias. 6. ed. São Paulo: RT, 2010.

FAORO, Atílio. O Brasil não quer a lei da palmada, Sr. Presidente! Disponível em: <http://www.ipco.org.br/home/nacional/o-brasil-nao-quer-a-lei-da-palmada-sr-presidente>. Acesso em 21 abr. 2012. 
MOREIRA, Jacqueline de Oliveira; BORGES, Adriana Araújo Pereira. A Castração e Seus Destinos na Construção da Paternidade. Rio de Janeiro: Psicologia Clínica, 2008.

OAB: lei da palmada será inócua sem políticas efetivas de educação familiar. Disponível em: <http://agenciabrasil.ebc.com.br/noticia/2011-12-15/para-oab-lei-da-palmada-sem-orientacaofamiliar-e-inocua>. Acesso em: 16 abr. 2012.

PEREIRA JR, Antonio Jorge. Usurpação do poder familiar e irresponsabilidade do estado na campanha de prevenção de AIDS, DST e gravidez. Disponível em:

<http://www.ibdfam.org.br/novosite/artigos/detalhe/618>. Acesso em: 04 de jul. 2012.

PODER Judiciário do Estado do Rio Grande do Sul. Disponível em:

<http://google4.tj.rs.gov.br/search?q=cache:www1.tjrs.jus.br/site_php/consulta/consulta_proc esso.php\%3Fnome_comarca\%3DTribunal\%2Bde\%2BJusti\%25E7a\%26versao\%3D\%26versao_fonetica\%3 D1\%26tipo\%3D1\%26id_comarca\%3D700\%26num_processo_mask\%3D71003450418\%26num_processo\% 3D71003450418\%26codEmenta\%3D4635090+71003450418\&site=ementario\&client=buscaTJ\&access =p\&ie=UTF-8\&proxystylesheet=buscaTJ\&output=xml_no_dtd\&oe=UTF .

$8 \&$ numProc $=71003450418 \&$ comarca $=$ Comarca+de+Santa+Maria\&dtJulg=09-04-

2012\&relator=Heleno+Tregnago+Saraiva>. Acesso em: 21 maio 2012.

PODER Judiciário do Estado do Rio Grande do Sul. Disponível em:

<http://google4.tj.rs.gov.br/search?q=cache:www1.tjrs.jus.br/site_php/consulta/consulta_proc esso.php\%3Fnome_comarca\%3DTribunal\%2Bde\%2BJusti\%25E7a\%26versao\%3D\%26versao_fonetica\%3 D1\%26tipo\%3D1\%26id_comarca\%3D700\%26num_processo_mask\%3D71002907194\%26num_processo\% 3D71002907194\%26codEmenta\%3D3911069+71002907194\&site=ementario\&client=buscaTJ\&access =p\&ie=UTF-8\&proxystylesheet=buscaTJ\&output=xml_no_dtd\&oe=UTF-

8\&numProc=71002907194\&comarca $=$ Comarca+de+Jaguar\%E3o\&dtJulg=13-12-

2010\&relator=Edson+Jorge+Cechet >. Acesso em: 21 maio 2012.

SOUZA, Nayane Valente de. Poder Familiar: os limites dos castigos nos filhos. Disponível em: <http://repositorio.uniceub.br/bitstream/123456789/1408/1/20725581.pdf >. Acesso em: 20 maio 2012.

VENOSA, Sílvio de Salvo. Direito civil: direito de família. 5. ed. São Paulo: Atlas, 2005

ZAGURY. Tania. Limites sem Trauma, construindo cidadãos. 4. ed. São Paulo: Record, 2004.

ZAMBERLAM, Cristina de Oliveira. Os novos paradigmas da família contemporânea - Uma perspectiva interdisciplinar. Rio de Janeiro: Renovar, 2001.

Recebido em: 1 maio 2013

Revisões requeridas: 15 jul. 2013

Aprovado em: 19 jul. 2013 